\title{
The Association Between Interleukin-10 Gene Polymorphism And Il-10 Levels In Geohelminth Positive Adolescents And Adults In West Sumatera
}

\author{
Nurhayati $^{1}$, Nuzulia Irawati ${ }^{2}$, Eryati Darwin ${ }^{3}$, Nur Indrawati Lipoeto $^{4}$ \\ \{nurhayati@med.unand.ac.id ${ }^{1}$, nuzuliairawati@med.unand.ac.id ${ }^{2}$, eryatidarwin@med.unand.ac.id ${ }^{3}$ \} \\ Department of Parasitology, Faculty of Medicine, Universitas Andalas, \\ Padang, Indonesia ${ }^{1,2}$ \\ Department of Histology, Faculty of Medicine, Universitas Andalas, Padang Indonesia ${ }^{3}$ \\ Department of Nutritional Science, Faculty of Medicine, Universitas Andalas Padang, Indonesia ${ }^{4}$
}

\begin{abstract}
Geohelminth infection can cause nutritional disorder and anemia. Behind these negative effect, worms turned out to provide protective effect on a number of diseases such as allergies and inflammations. This is related to its ability to modulate the host's immune response via Th-2, characterized by an increase production of Interleukin 10 (IL-10) which is an anti inflammatory cytokine. The genes encoding IL-10 are known to have single nucleotide polymorphism (SNP) in the promoter regions affecting IL-10 production. This study aimed to investigate the IL-10 polymorphisms in geohelminth infections and control and assess their effects on IL-10 production. This research was a comparative crosssectional study. Samples were geohelminth-infected individuals aged $>11$ years old. Age, gender, and BMI category are matched between cases and controls. IL-10 levels were measured by using the ELISA method. IL-10 gene polymorphism was examined by using PCR and the Sanger sequencing method to detect SNP at rs1800896, rs1800871 and rs1800872. All subjects infected with geohelminth in this study were classified as mild infections. There was a significant increase in IL-10 levels in geohelminth-infected individuals when compared to controls $(\mathrm{p}<0.05)$. There was no association between the IL10 gene polymorphism and the incidence of geohelminth infection $(p>0.05)$, but there was a significant association between GA genotype in rs1800896 with elevated levels of IL-10 in geohelminth infections ( $\mathrm{p}<0.05$ ). We concluded that high levels of IL-10 in geohelminth infections were also influenced by IL-10 gene polymorphism, specially the GA genotype at rs1800896.
\end{abstract}

Keywords: Geohelminth, IL-10 gene polymorphism, IL-10 levels.

\section{Introduction}

Intestinal worm parasites are one of the most common causes of chronic infection in humans. Approximately 1.5 billion people are infected with soil-transmitted helminths worldwide by one or more types of intestinal worms, especially by worms that are transmitted through the soil, also called intestinal geohelminth or soil-transmitted helminths, such as Ascaris lumbricoides, Necator americanus, Ancylostoma duodenale, and Trichuris trichiura [1].

Geohelminth infection is more frequent and persistent in children and individuals living in endemic areas, due to exposure at all times of their lives, begin immediately after birth to 
adulthood. The highest prevalence is found in children of primary school age, but can also be related to adults who are influenced by the surrounding environment and work [1].

Geohelminth can cause nutritional disorders and anemia, especially in children with less nutritional intake [2]. Behind these negative effects, worms turned out to provide protective effects on some diseases such as allergies, which have been proven by many researchers $[3,4,5]$. This turned out to be related to the ability of worms to modulate the immune response of the host [6,7].

In chronic infections, worms trigger the differentiation of macrophages from classically activated macrophages (CAMs) to alternatively activated macrophages (AAMs), an increase in the number of T regulatory cells (Treg) which are characterized by the production of Interleukin10 (IL-10) anti-inflammatory cytokines, and/or Transforming Growth Factor $\beta$ (TGF- $\beta$ ) [8,9]. IL-10 is the most often discussed anti-inflammatory cytokine compared with other cytokines and is considered to be one of the key cytokines in neutralizing the effects of inflammatory responses that arise in several diseases.

Many studies have shown that in geohelminth infections there were higher levels of IL-10 when compared with individuals who were not infected with geohelminth $[9,10,11,13]$. Even in children aged 13-18 months whose mothers were infected with geohelminth, they also had higher levels of IL-10 than children whose mothers were not infected with geohelminth [12]. Nevertheless, some researchers reported that there was no difference in IL-10 levels between the people who were infected by geohelminth and the people who were not infected by geohelminth [13]. This is because IL-10 production is influenced by many factors, one of which is a variant of gene alleles (polymorphism) [14].

The IL-10 gene that is located on chromosome 1 in 1q21-32 has various genetic variants that are associated with variations in IL-10 production [15]. There are many genetic variants of the IL-10 gene, but the most widely studied are three single nucleotide polymorphism (SNPs), namely -1082 Guanine (G)> Adenine (A) (rs1800896), -819 Cytosine (C)> Thymine (T ) (rs1800871) and -592 C> A (rs1800872), because they are located in the promoter region associated with transcription. A study of healthy volunteers reported that A alleles from A1082G were associated with low IL-10 production in Peripheral Blood Mononuclear Cell (PBMC) cultures stimulated by concanavalin A [16]. Whereas $\mathrm{G}$ allele was associated with an increase in plasma IL-10 levels. SNP at -1082 is often studied about susceptibility and protective effects to certain diseases.

Until now, there have been no reports of the effect of IL-10 polymorphism on IL-10 levels in adult individuals infected with geohelminth. It is known that children's immunity is not developing as perfect as adults, and it is well known that age is associated with certain levels of cytokines. For this reason, it is necessary to conduct a study that examines IL-10's polymorphism in geohelminth infection and its effect on adolescent and adult IL-10 production.

\section{Subjects and Methods}

\subsection{Location and Population of study}

This research was conducted in West Sumatra, Indonesia. Subjects were geohelminth-positive children aged $>11$ years old from three elementary schools in Padang Pariaman and geohelminth-positive farmers from the outskirts of Padang. None of the subjects was using allergy or steroid medication. Cancer and tuberculosis sufferers were also eliminated from the 
study. The total sample size was 41 individuals along with the age, gender and BMI categorymatched control samples of uninfected individuals.

\subsection{Ethical consent}

Permission was obtained from the Ethics Commission of Faculty of Medicine of Andalas University in Padang. All subjects were briefed about the study including the objectives, risks, and benefits of the study and gave consent to be involved. For those younger than 18, consent forms were signed by their parents.

\subsection{Stool sample collection and examination}

Stool examinations were conducted at the Parasitology Laboratory of Faculty of Medicine of Andalas University by using a direct wet mount with iodine [17] and by the Kato Katz method [19] to calculate the number of geohelminth eggs.

\subsection{Collection of blood samples}

Blood was taken by using an aseptic procedure from the mediana cubiti vein by trained personnel, using $3 \mathrm{cc}$ syringe. An amount of $2 \mathrm{cc}$ blood was collected in an EDTA tube for DNA, and $1 \mathrm{cc}$ was collected into tube marked by a yellow cap for ELISA examination. The samples were taken to the Biomedical Laboratory of Faculty of Medicine of Andalas University for analysis.

\subsection{Measurement of levels of IL-10}

The IL-10 levels were measured according to the manufacturer's instructions by using a Human IL-10 ELISA Kit (Sensitivity $2.59 \mathrm{pg} / \mathrm{ml}$, assay range $5 \mathrm{pg} / \mathrm{ml}-1500 \mathrm{pg} / \mathrm{ml}$, Catalog Number E0102Hu, Bioassay Technology Laboratory, Shanghai) and read with an ELISA reader at 450 $\mathrm{nm}$ by using an automatic microplate reader (xMark, BioRad, USA).

\subsection{Genotyping}

Genomic DNA was isolated from blood samples by using the GF-1 Blood DNA isolation kit, the Vivantis brand (Catalog No. GF-BD-050 and GF-BD-100). DNA isolation was carried out according to the kit procedure, consisting of the sample preparation, cell lysis, DNA binding, washing, and DNA elution.

IL-10 promoter genotyping to detect SNP -1082 G/A (rs1800896), -819 C/T (rs1800871), and -592 C/A (rs1800872), was done by using PCR and sequencing method (Sanger method). The three SNPs were in an adjacent position so that they use one specific primer pair that has been designed with the Genious, 5'-TCTGAAGAAGTCCTGATGTC -3 '(forward), and 5'ATGAATACCCAAGACTTCTCC -3' programs (reverse).

PCR was carried out at a final volume of $25 \mu \mathrm{L}$ containing $100 \mathrm{ng}$ DNA template, $12.5 \mathrm{ul}$ My Taq HS Red Mix Bioline (Catalog No. BIO-25047), $300 \mathrm{nmol} / \mathrm{ul}$ primer IL10 promoter-F and IL10 promoter-R. The PCR stages were as follows: initial denaturation at $95^{\circ} \mathrm{C}$ for 3 minutes, followed by 35 cycles of a series of processes consisting of denaturation at $95^{\circ} \mathrm{C}$ for 30 seconds, annealing at $63^{\circ} \mathrm{C}$ for 40 seconds, and elongation at $72^{\circ} \mathrm{C}$ for 1 minute. The PCR process ended with the final elongation step at $72{ }^{\circ} \mathrm{C}$ for 5 minutes. PCR products were observed 
by electrophoresis by using $1.5 \%$ agarose gel. After being dyed with DNA GelRed, it was observed under GelDoc. PCR products were measuring $813 \mathrm{bp}$. The remaining PCR products were purified, then $20 \mathrm{ul}$ PCR products that have been pure would be sent for sequencing. Sequencing data were analyzed with the help of Geneious Bioinformatics software.

\subsection{Data analysis}

In the measurement of data normality, data from IL-10 levels were not normally distributed, although data transformation has been carried out. So that the difference in IL-10 polymorphism between geohelminth and control infections was analyzed by using chi-square/Kolmogorov Smirnov test. The relationship between IL-10 gene polymorphism and IL-10 levels was analyzed by using Mann-Whitney U/Kruskal Wallis test.

\section{Results}

\subsection{Characteristics of Subjects}

Out of a total of 41 geohelminth-infected individuals, A. lumbricoides was the most common cause $(43.9 \%)$, followed by hookworm $(29.3 \%)$, T. trichiura (14.6\%), co-infection of $A$. lumbricoides and T. trichiura (9.8\%), and co-infection of Ascaris lumbricoides and hookworm $(2.4 \%)$. All subjects infected with geohelminth were classified as mild infections (Table 1).

Table 1.Characteristics of Subjects

\begin{tabular}{|c|c|c|}
\hline \multirow{2}{*}{ Characteristics } & Geohelminth Infections & Controls \\
\hline & $\mathrm{N}=41$ & $\mathrm{~N}=41$ \\
\hline \multicolumn{3}{|l|}{ Gender } \\
\hline Man $\mathrm{f}(\%)$ & $13(31,7)$ & $13(31,7)$ \\
\hline Woman $\mathrm{f}(\%)$ & $28(68,3)$ & $28(68,3)$ \\
\hline Age (years) (median, range) & $39(11-65)$ & $39(11-65)$ \\
\hline Weight (kg) (median, range) & $46(29-69)$ & $50(31-70)$ \\
\hline Height $(\mathrm{cm})($ mean \pm SD $)$ & $146,8 \pm 8,8$ & $148,8 \pm 11,3$ \\
\hline $\mathrm{BMI}(\mathrm{kg} / \mathrm{m} 2)($ mean $\pm \mathrm{SD})$ & $20,7 \pm 3,9$ & $22 \pm(3,5)$ \\
\hline \multicolumn{3}{|l|}{ BMI category } \\
\hline Underweight $\mathrm{f}(\%)$ & $15(36,6 \%)$ & $15(36,6 \%)$ \\
\hline Normal $\quad \mathrm{f}(\%)$ & $16(41,5 \%)$ & $16(41,5 \%)$ \\
\hline Overweight $\mathrm{f}(\%)$ & $4(9,8 \%)$ & $4(9,8 \%)$ \\
\hline Obesity 1 f (\%) & $5(12,2 \%)$ & $5(12,2 \%)$ \\
\hline \multicolumn{3}{|l|}{ Geohelminth type } \\
\hline A. lumbricoides $\mathrm{f}(\%)$ & $18(43,9)$ & \\
\hline T. trichiura $\mathrm{f}(\%)$ & $6(14,6)$ & \\
\hline Hook worm f $(\%)$ & $12(29,3)$ & \\
\hline A.lumbricoides + T. trichiura $\mathrm{f}(\%)$ & $4(9,8)$ & \\
\hline A.lumbricoides + Hook worm f $(\%)$ & $1(2,4)$ & \\
\hline EPGS (median, range) & $13(2-1543)$ & \\
\hline \multicolumn{3}{|l|}{ Intensity of infection } \\
\hline Mild f (\%) & $41(100 \%)$ & \\
\hline Moderate and severe f $(\%)$ & $0(0 \%)$ & \\
\hline
\end{tabular}

$\mathrm{N}=$ population, $\mathrm{f}=$ frequency, $\mathrm{BMI}=$ Body mass index, $\mathrm{SD}=$ Standard Deviation,

EPGS = eggs per gram of stool 


\subsection{Comparison of IL-10 levels in geohelminth infections and controls}

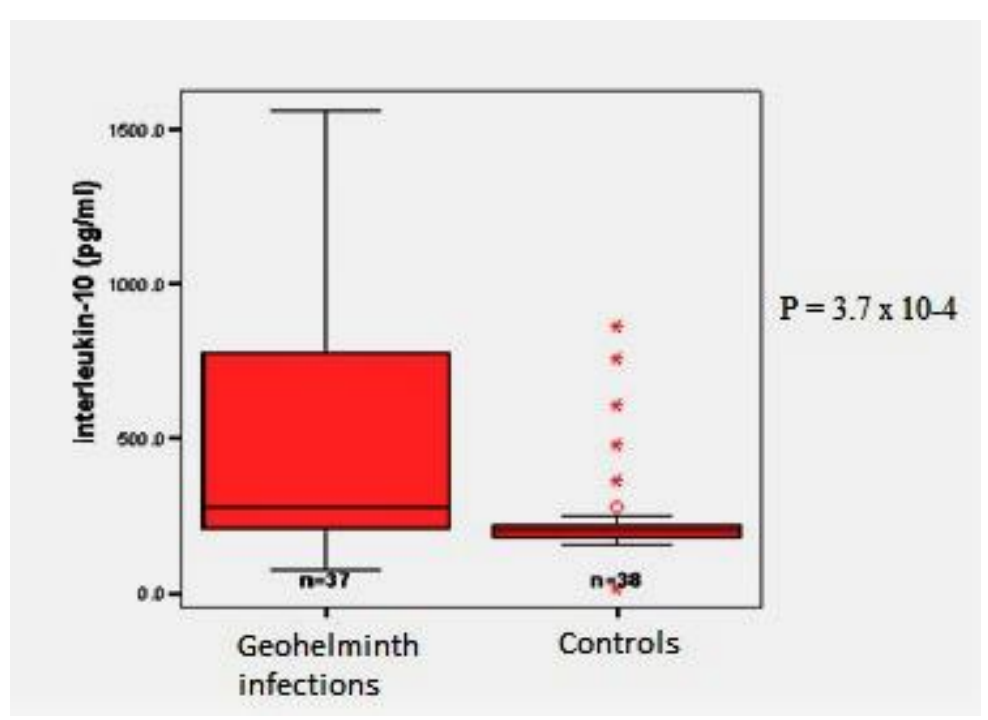

Fig. 1. Differences of IL-10 Levels in Geohelminth Infection and Control.

The plots box shows the median value (horizontal center line), interquartile range (edge box), and $95 \%$ confidence intervals (bars).

IL-10 levels in the study subjects ranged from 16 to $1564 \mathrm{pg} / \mathrm{ml}$. As shown in Figure 1, there was an increase in IL-10 levels in geohelminth-infected subjects (median $=278 \mathrm{pg} / \mathrm{ml}$ ) compared to controls (median $=204 \mathrm{pg} / \mathrm{ml}$ ); with the Mann Whitney test, the difference was very significant, $\mathrm{P}=3.7 \times 10-4$.

\subsection{Relationship of IL-10 Regio Promoter Genes Polymorphism with IL- 10 Levels in Geohelminth Infection.}

There are 2 types of genotypes at rs1800896, namely, AA is the highest frequency of $75 \%$ and GA with a frequency of $25 \%$, whereas GG genotype is not found. At rs 1800871 there are three types of genotypes, namely CC, TC, and TT, with a frequency of $6.6 \%, 50 \%$, and $43.4 \%$. At rs 1800872 there are also three types of genotypes, namely CC, AC and AA with a frequency of $9.2 \%, 50 \%$, and $40 \%$. There are no significant differences in genotypic frequency between geohelminth infection and controls.

Geohelminth-infected subjects with AA genotypes at rs1800896 (-1082) have the lowest IL-10 levels (73 pg ml - $1067 \mathrm{pg} / \mathrm{ml}$ with a median of $255 \mathrm{pg} / \mathrm{ml}$ ). IL-10 levels in the GA genotype ranged from $284 \mathrm{pg} / \mathrm{ml}-1564 \mathrm{pg} / \mathrm{ml}$, with a median of $916 \mathrm{pg} / \mathrm{ml}$. With the Mann Whitney statistical test, there were significant differences in IL-10 levels produced by geohelminth-infected subjects who have GA genotypes compared to AA genotypes at rs1800896 (-1082) with a value of $\mathrm{P}=0.007, \mathrm{CI}=95 \%$ (Table 2). Whereas in control, there was no significant difference in IL-10 levels in both genotypes. 
Table 2. Relationship of the IL-10 Regio Promoter Polymorphism with IL-10 Levels in Subjects Infected

\begin{tabular}{llll}
\hline Markers & Genotype & IL-10 level (pg/ml) & P \\
\hline \multirow{2}{*}{ rs1800896 A $/ \mathrm{G}$} & AA & $255(73-1067)$ & 0,007 e \\
& GA & $916(284-1564)$ & \\
$\operatorname{rs} 1800871 \mathrm{C}^{\mathbf{c}} / \mathrm{T}$ & CC & $946(798-1094)$ & 0.065 \\
& TC & $364(175-1564)$ & \\
& TT & $248(73-1067)$ & 0,490 \\
rs1800872 Cd/A & CC & $501(73-1094)$ & \\
& AC & $364(175-1564)$ & \\
\hline
\end{tabular}

${ }^{\mathrm{a}}$ median (range) ${ }^{\mathrm{b}, \mathrm{c}, \mathrm{d}}$ ancestral allele ${ }^{\mathrm{e}}$ significantly different

\section{Discussion}

In this study, the geohelminth-infected group had higher IL-10 levels than the control group. The results of this study were in line with the research of Fugueirido et al. (2010), which found that IL-10 was increased in people infected with geohelminth, although the method they used was different from this study.

A study conducted by Sanchez (2015) did not find any association between the levels of IL10 and the geohelminth infection in Honduran children, although the principle of measuring IL10 used was almost the same as this study. This may be due to differences in the age of the research subjects. In this study, the age of subjects ranged from 11 years old to 65 years old, where the immune organs have been fully developed, while the research subjects at Sanchez were aged 7-15 years old. At the age of 11 years and above, the intensity of helminths decreases and the levels of Th2 cytokines increase (IL-9, IL-10, and IL-13), which suggests that the Th2 response is associated with increased age [16].

High levels of IL-10 in geohelminth infections are caused by the ability of the worms to modify the immune response towards Th2, increasing type- 2 cytokines, such as IL- 4 , IL-5, and IL-10. Worms also can trigger regulator responses through the T regulator to produce IL-10 and TGF $\beta[8,9]$.

In this study, almost all study subjects examined had SNP in the promoter region of IL-10 gene $(94.7 \%)$. This was consistent with the result of a previous study [19], which stated that polymorphism in IL-10 was very high.

In rs1800896 there were only two genotypes, namely AA and GA. Most subjects had AA genotypes (75\%). No GG genotype at rs1800896 was found in the study subject. This was in line with the results of previously reported studies, that AA genotypes were very specific to the Asian population, even reaching $97.5 \%$, while the GG genotype was not found in Asian populations, but was more common in Caucasia populations [20,21].

The genotype frequency of AA and GA at rs1800896 is almost the same between geohelminth infection and control. The frequency of TC genotypes at rs1800871 and AC genotypes at rs 1800872 was seen to be slightly higher in controls than in cases, after statistical tests there was no significant difference, indicating that there is no association between the genotype frequency and the incidence of geohelminth infection as was reported by Fugueirido et al., in 2013. 
IL-10 levels, like other cytokines, are influenced by certain diseases; their secretion is also influenced by the gene polymorphisms that encode them, especially polymorphisms located in the promoter region. About 50-70\% variation of IL-10 synthesis is influenced by genetic factors [22]. Other factors that influence cytokine secretion are smoking, body mass index and age. In this study, the influence of BMI and age has been abolished.

In vitro IL-10 expression is mainly determined by a polymorphism in the position of -1082 G/A (rs1800896). Several studies have shown that the genotypic sequences of AA, AG, and GG had low, medium and high IL-10 levels (Stanczuk et al., 2001). In this study, geohelminthinfected subjects with AA genotypes at rs1800896 (-1082) had the lowest IL-10 levels, whereas GA genotypes had high IL-10 levels. In this study, geohelminth-infected subjects with AA genotype at rs1800896 had the lowest IL-10 levels, whereas GA genotypes had high levels of IL-10. There was a significant difference in the levels of IL-10 produced by geohelminthinfected subjects who had GA genotypes versus the AA genotype at rs1800896, whereas, in the controls, there was no significant difference in the levels of IL-10 in both genotypes of the marker. These findings indicated that high levels of IL-10 in geohelminth infections were also influenced by IL-10 gene polymorphism, especially the GA genotype at rs1800896.

We acknowledge the limitations of this cross-sectional study, which prevent the conclusion on the causal relationship between IL-10 gene polymorphism and IL-10 1evel. In this study we did not know whether the subjects studied had been infected for a long time (chronically) or had just been infected, but by looking at the living environment, the work that has been occupied for a long time, and the history of not getting deworming drugs in the past years, either intestinal worm medicine or elephantiasis medication, it can be assumed that the research subjects have been chronically infected.

It is clear that further and specifically design investigations are needed to clarify the relationship between IL-10 levels, GA genotype at 1800896, and protective effect in geohelminth infection.

\section{Conclusion}

This study has shown that geohelminth infection significantly increased IL-10 levels, but a significant increase in IL-10 levels was only found in geohelminth infected individuals who had the GA genotype at rs 1800896. This shows that apart from the influence of geohelminth infection, there is also the role of IL-10 gene polymorphism in increasing IL-10 levels in individuals infected with geohelminth, especially the GA genotype at 1800896 .

\section{References}

[1] WHO, 2018. 'Soil-transmitted helminth infections'. Available at https://www.who.int/newsroom/fact-sheets/detail/soil-transmitted-helminth-infections. (Accessed 25 May 2018).I

[2] Hotez, P.J., Brindley, P'.J., Bethoni, J.M, King, C.H., Pearce, E.J., Jacobson, J., et al., 2008. Helminth infections: the great neglected tropical diseases'. The Journal of Clinical Invest,118(4), pp1311-1321.

[3] Smits, H.H., Everts, B., Hartgers, F.C., and Yazdanbakhsh, M., 2010. 'Chronic Helminth Infections Protect Against Allergic Diseases by Active Regulatory Processes'. Curr Allergy Asthma Rep, 10(1), pp3-12.

[4] Hamid, F., Amoah, A.S., van Ree, R. and Yazdanbakhsh, M., 2015. 'Helmint.h-induced IgE and protection against allergic disorders'. Curr Top Microbiol Immunol, 388, pp91-108. 
[5] Stein, M., Greenberg, Z., Boaz, M, Handzel, Z.T., .Meshesha, M.K., Bentwich, Z., 2016. 'The Role of Helminth Infection and Environment in The Development of Allergy: A Prospective Study of Newly-Arrived Ethiopian Immigrants in Israel'. PLoS Negl Trop Dis, 10(1) [online] Availabe at: https://journals.plos.org/plosntds/article ( Accessed 20 March 2016).

[6] Van Riet, E., Hartgers, F.C., and Yazdanbakhsh, M., 2007. 'Chronic helminth infections induce immunomodulation: consequences and mechanisms'. Immunobiol, 212(6), pp475-90.

[7] Hewitson, J.P., Grainger, J.R. and Maizels, R.M., 2009. 'Helminth immunoregulation: The role of parasite secreted proteins in modulating host immunity'. Mol Biochem Parasitol, 167(1), pp111.

[8] Matisz, C.E., McDougal, J.J.L., Sharkey, K,A, and McKay, D.M., 2011. 'Helminth parasites and the modulation of joint inflammation'. J Parasitol Res. Availabe at: https://www.ncbi.nlm.nih.go/pmc/articles/PMC3092582/ (Accessed: 12 February 2014).

[9] Maizels, R. and Yazdanbakhsh M., 2008. 'T-cell regulation in helminth parasite infections: implications for inflammatory diseases'. Chem Immunol Allergy, 94, pp112-123.

[10] Figueiredo, C.A., Barreto, M.1., Alcantara-Neves, N.M., Rodrigues, L.C., Cooper, P.J., Cruz, A.A., et al., 2013. 'Coassociations Between Il-10 Polymorphisms, Il-10 Production, Helminth Infection, And Asthma/Wheeze In An Urban Tropical Population In Brazil'. J Allergy Clin Immunol, 131(6), pp1683-1690.

[11] Turner, J.D., Faulkner, H., Kamgno, J., Cormont, F., Van Snick, J., Else, K.J., et al., 2003. 'Th2 cytokines are associated with reduced worm burdens in a human intestinal helminth infection'. J Infect Dis, 188(11), pp1768-1775.

[12] Arinola, G.O., Morenikeji, O.A., Akinwande, K.S., Alade, A.O., Olateru-Olagbegi, O., Alabi, P.E., et al., 2015. 'Serum Levels of Cytokines and IgE in Helminth-Infected Nigerian Pregnant Women and Children'. Ann Glob Health, 81(5), pp689-693.

[13] Mehta, R.S., Rodriguez, A., Chico, M., Guadalupe, I., Brancano, N., Sandoval, C., et al., 2012. 'Maternal geohelminth infections are associated with an increased susceptibility to geohelminth infection in children: a case control study'. PLoS Negl Trop Dis, 6(7) [online]. Availabe at: https://journals.plos.org/plosntds/article (Accessed: 24 August 2014).

[14] Sanchez, A.L., Mahoney, D.L., and Gabrie, J.A., 2015. 'Interleukin-10 and soil-transmitted helminth infections in Honduran children'. BMC Res Notes, 8,55 [online]. Availabe at: https://www.ncbi.nlm.nih.gov/pmc/articles /PMC4347577 (Accessed 15 January 2016).

[15] Trifunovic, J., Miller L., Debeljak, Ž., and Horvat, V., 2015. 'Pathologic patterns of interleukin 10 expression - A review'. Biochem Medica, 25(1), pp36-48.

[16] Jin, X., Hu, Z, Kang, Y., Liu, C., Zhou, Y., Wu, X., et al., 2012. 'Association of IL-10-1082 G/G genotype with lower mortality of acute respiratory distress syndrome in a Chinese population'. Mol Biol Resp, 39, pp1-4.

[17] Turner, D.M., Williams, D.M., Sankaran D., Lazarus, M., Sinnott, P.J., Hutchinson, I.V., 1997. 'An investigation of polymorphism in the interleukin-10 gene promoter'. Eur J Immunogenet, 24, pp 1-8.

[18] WHO, 1991. Basic Laboratory Methods in medical parasitology. Available at https://www.who.int/malaria/publications. (Accessed 10 September 2015).

[19] Peters, P.A., El Alamy, M., Warren, K.S., and Mahmoud A.A., 1980. 'Quick Kato smear for field quantification of Schistosoma mansoni eggs'. Am J Trop Med Hyg, 29(2), pp217-219.

[20] Eskdale, J., Kube, D., Tesch, H. and Gallagher, G., 1997. 'Mapping of the human IL10 gene and further characterization of the 5 flanking sequence'. Immunogenetics, 46, pp8120-8128.

[21] Meenagh, A., Williams, F., Ross, O., Patterson, C., Gorodezky, C., Hammond., et al., 2002. 'Frequency of Cytokine polymorphisms in populations from western Europe, Africe, Asia, the Middle East and South America. Hum Immunol, 63, pp1055-1061.

[22] Hoffman, S.C., Stanley, E.M., Cox, E.D., Di Merucio, B..S, Koziol, D.E., Harlan, D,M., at al., 2002. 'Ethnicity greatly influences cytokine polimorphisms distribution'. Am J Transplant, 2, pp560-567. 
[23] Donger, C., Georges, J.L., Nicaud, V., Morrison, C., Evans, A., Kee, F., et al., 2001. 'New polymorphisms in the interleukin-10 gene-relationships to myocardial infarction'. Eur J Clin Invest, 31, pp9-14.

[24] Stanczuk, G.A., Sibanda, E.N., Perrey, C., Chirara, M., Pravica, V., Hutchinson I.V., Tswana. S.A., 2001. 'Cancer of the uterine cervix may be significantly associated with a gene polymorphism coding for increased IL-10 production'. Int J Cancer, 15;94(6), pp792-794. 